\title{
Interaction of Oxygen with the (111) Surface of $\mathrm{NaAu}_{2}$
}

Emma J. Kwolek ${ }^{\mathrm{a}, *}$, Roland Widmer ${ }^{\mathrm{b}}$, Oliver Gröning ${ }^{\mathrm{b}}$, Okan Deniz ${ }^{\mathrm{b}}$, Holly Walen ${ }^{\mathrm{a}}$, Chad D. Yuen $^{\mathrm{a}, 1}$, Wenyu Huang ${ }^{\mathrm{a}}$, Deborah L. Schlagel ${ }^{\mathrm{c}}$, Mark Wallingford ${ }^{\mathrm{c}}$, C. R. Brundle ${ }^{\mathrm{d}}$, Patricia A. Thiel $^{\text {a,c,e }}$

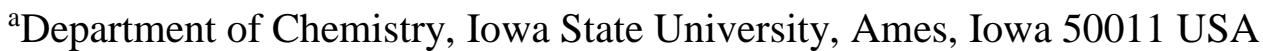

bnanotech@surfaces Laboratory, EMPA, Swiss Federal Laboratories for Materials Science and Technology, Ueberlandstrasse 129, 8600 Duebendorf, Switzerland

${ }^{\mathrm{c}}$ The Ames Laboratory, Ames, Iowa 50011 USA

${ }^{\mathrm{d}}$ C.R. Brundle \& Associates, 4215 Fairway Drive, Soquel, California 95073

e Department of Materials Science \& Engineering, Iowa State University, Ames, Iowa 50011

USA

\begin{abstract}
.
$\mathrm{NaAu}_{2}$, in powder form, is known to be an active catalyst for $\mathrm{CO}$ oxidation. The goal of the present study is to elucidate the interaction of one reactant, molecular oxygen, with a singlecrystal surface of this material, $\mathrm{NaAu}_{2}(111)$. Exposing the clean surface to gas-phase molecular oxygen produces three types of oxygen on the surface. One type is bound in spurious carbonate that forms during exposure. The second is adsorbed atomic oxygen that interacts both with $\mathrm{Na}$ and $\mathrm{Au}$. The third type is atomic oxygen that interacts mainly or only with $\mathrm{Na}$. We propose that the last species is an oxide of $\mathrm{Na}$ distributed throughout the surface and near-surface region. Its formation is accompanied by surface segregation of $\mathrm{Na}$.
\end{abstract}

Keywords: XPS, $\mathrm{NaAu}_{2}$, intermetallic, oxidation

\section{Introduction.}

Intermetallics are potential alternatives to precious metal catalysts for certain reactions.[1] For instance, quasicrystalline $\mathrm{AlCuFe}$ shows good activity and stability in steam reforming of methanol,[2] and both $\mathrm{Pd}-\mathrm{Ga}$ compounds and $\mathrm{Al}_{13} \mathrm{X}_{4}(\mathrm{X}=\mathrm{Fe}, \mathrm{Co})$ intermetallics show promise for selective hydrogenation of alkynes.[3, 4] Independently, there has been great interest in $\mathrm{Au}$ — especially as supported nanoparticles [5-8] and as nanoporous solids [9, 10] — as an effective low-temperature catalyst for oxidation reactions.[11] The reasons for the intriguing catalytic properties of both classes of catalyst are diverse, and remain under active investigation.

The possibility of finding new catalysts at the nexus of these two types of materialsintermetallics and nano-structured $\mathrm{Au}$ - led to a recent investigation of the catalytic properties of an Au-rich intermetallic, $\mathrm{NaAu}_{2}$.[12] The $\mathrm{CO}$ oxidation reaction was chosen because it is important, and also it is a benchmark indicator of the oxidative activity of $\mathrm{Au}$ in its various forms.[13] Powders of this material showed excellent activity for CO oxidation, in a range of relatively low temperatures (T) between $300 \mathrm{~K}$ and $400 \mathrm{~K}$.[12] In the model developed for this reaction, molecular oxygen adsorbs at a site involving multiple $\mathrm{Au}$ and $\mathrm{Na}$ atoms, including $1 \mathrm{Na}$

${ }^{1}$ Present address: Department of Chemistry and Biochemistry, Augustana College, Rock Island, Illinois 61201 USA 
atom that moves above the surface plane, i.e. it 'pops out'. The molecule can react directly with $\mathrm{CO}_{\mathrm{ad}}$ to form an intermediate $\mathrm{OOCO}_{\mathrm{ad}}$, and ultimately $\mathrm{CO}_{2, \mathrm{~g}}$ and $\mathrm{O}_{\mathrm{ad}}$.

Motivated by this report, we characterized the clean (111) surface of single-crystal $\mathrm{NaAu}_{2}$ in ultrahigh vacuum (UHV), to determine its stability relative to the bulk, and hence the suitability of the (111) termination as a model for the active catalyst surface.[14] We found that the surface could exist in one of two conditions. In one, both low-energy electron diffraction (LEED) and X-ray photoelectron diffraction (XPD) were consistent with expectations from bulk structure, with some evidence of disorder. Furthermore, STM showed mesa-like features whose flat tops likely exhibited bulk-termination - though atomic order could not be resolved. The regions separating the mesas must be regarded as significant defect regions. To provide a more graphic review, Fig. 1 shows STM images and line profiles, together with diffraction data, for this state of the clean surface. In this paper, we present a re-analysis of the surface composition in this state using XPS and Auger electron spectroscopy (AES), showing that the surface is Naenriched.

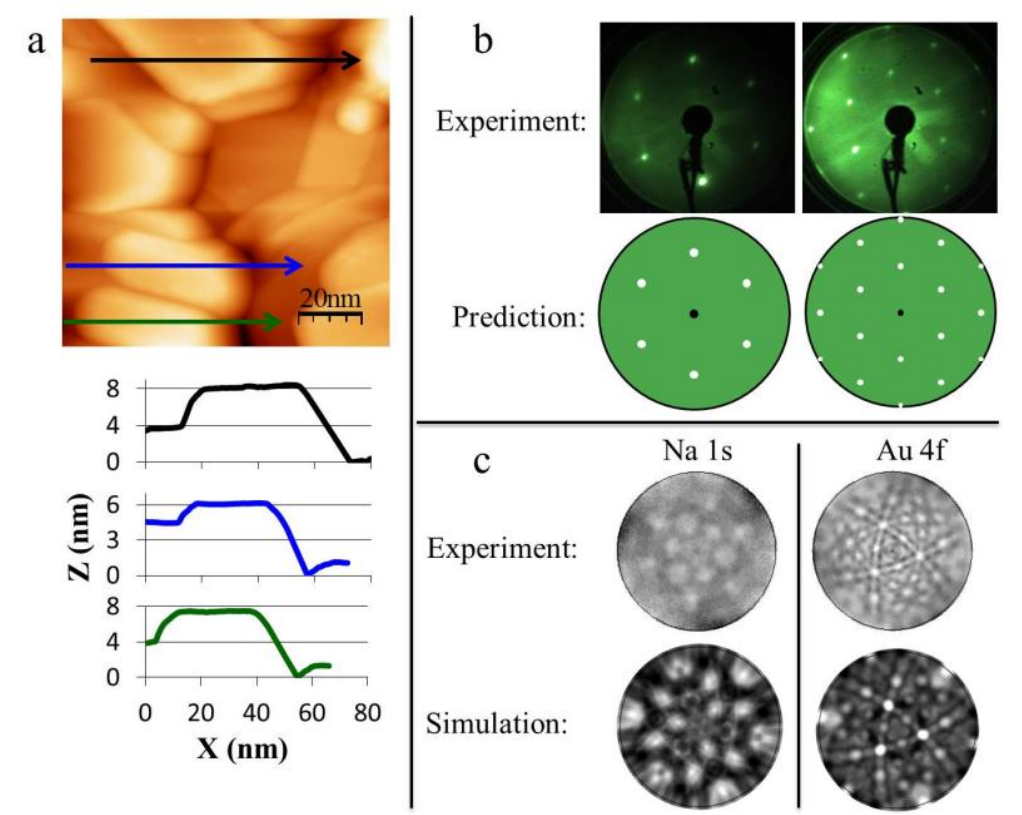

Figure 1: STM and diffraction data for the clean surface of $\mathrm{NaAu}_{2}$. (a) Typical STM image (top) and line profiles (bottom), showing the mesa-like structure. (b) Low-energy electron diffraction patterns. Top two patterns show images measured at $27.0 \mathrm{eV}$ (left) and $45.0 \mathrm{eV}$ (right). Lower two patterns show images predicted for a bulk-terminated surface at these energies. (c) X-ray photoelectron diffraction patterns using $\mathrm{Na} 1 \mathrm{~s}$ and $\mathrm{Au} 4 \mathrm{f}$ photoelectrons, both measured with an $\mathrm{Al} \mathrm{K \alpha}$ source (top) and simulated (bottom).

In the second condition, the surface was Na-depleted/Au-enriched. Na depletion was attributed both to preferential sputtering and desorption at elevated temperature. Based on temperature programmed desorption (TPD), Na desorption began at about $450 \mathrm{~K}$. Since both processes (sputtering and heating) were employed repeatedly as part of the normal cleaning process between experiments, the samples could be used only for a limited number of experiments before pure, crystalline Au precipitated irreversibly. Prior to this point, surface $\mathrm{Na}$ could apparently be replenished from the near-surface reservoir. 
With this as background, we now investigate the interaction of oxygen with the $\mathrm{NaAu}_{2}(111)$ surface. From energetics calculated previously,[12] certain predictions can be made. First, the residence time of molecular oxygen is so low that it should be unobservable under our experimental conditions. For the calculated adsorption energy, $\mathrm{E}_{\mathrm{ad}}$, of $-0.38 \mathrm{eV}$, the residence time at room temperature is of order $10^{-7}$ to $10^{-5} \mathrm{~s}$, assuming a pre-exponential desorption rate factor of $10^{12 \pm 1} \mathrm{~s}^{-1}$. Measurements take place over several hours following oxygen exposure. Low temperatures would be necessary to stabilize it on an appropriate time-scale, as is true in general for molecular oxygen on surfaces, e.g. [15-17]. Second, the barrier to dissociation of adsorbed molecular $\mathrm{O}_{2}$ is $1 \mathrm{eV}$, so irrespective of residence time, it would not dissociate at room temperature. Of course, both predictions apply to the ideal flat surface and, as noted above, the real surface is morphologically irregular. Our goal here is to determine whether atomic oxygen adsorbs and if so, whether its chemical state can be related to the surface composition and/or structure.

We first present analysis of XPS and AES data for the nominally-clean surface. We then describe standard oxygen adsorption experiments, which show that oxygen does adsorb, giving rise to two well-separated $\mathrm{O}$ 1s peaks in XPS. From these results, we develop a hypothesis that is tested with tailored experiments.

\section{Experimental Details.}

Single-crystal samples of $\mathrm{NaAu}_{2}$ were grown at the Materials Preparation Center of the Ames Laboratory via the Bridgman technique. All of the XPS experiments were carried out at EMPA in Dübendorf, Switzerland. All of the TPD experiments took place at the Ames Laboratory in Ames, Iowa, USA. Many aspects of the UHV instrumentation and experimental conditions for both sites have been described as part of our previous study of clean $\mathrm{NaAu}_{2}(111)$ [14]. Details unique to the oxygen adsorption experiments follow.

XPS experiments were conducted on the sample denoted B [14], which was re-polished for these oxygen experiments. Between each experiment, the sample was cleaned with two cycles of sputter-annealing. Each cycle consisted of $\mathrm{Ar}^{+}$ion bombardment at $1 \mathrm{keV}$ for 3 minutes at $300 \mathrm{~K}$, then annealing at $475 \mathrm{~K}$ for 15 minutes. For XPS, the sample was exposed to $\mathrm{O}_{2, \mathrm{~g}}$ by back-filling the chamber to a pressure of $1.0 \times 10^{-8}$ to $1.0 \times 10^{-7}$ mbar. Exposures are reported in units of Langmuir (L), where $1 \mathrm{~L}=1.33 \times 10^{-6} \mathrm{mbar}-\mathrm{s}$. In cases where the sample was annealed after exposure to $\mathrm{O}_{2, \mathrm{~g}}$, it was held at temperature for 20 minutes.

The XPS instrument was part of an Omicron ESCA UHV system, and consisted of a VSW $125 \mathrm{HR}$ electron analyzer and a twin anode (Mg and $\mathrm{Al}) \mathrm{X}$-ray source. Spectra were acquired at emission (take-off) angles, $\theta$, of $0^{\circ}, 60^{\circ}$, and $80^{\circ}$, defined with respect to the surface normal. Unless noted otherwise the energy step was $0.1 \mathrm{eV}$ and $\theta=60^{\circ}$ in the figures. Spectra at $\theta$ $=60^{\circ}$ were used for quantitative analyses because signal-to-noise was optimal. The pass energy was constant at $80 \mathrm{eV}$. The energy scale was calibrated with a $\mathrm{Au}(111)$ sample, using Au lines from the $5 \mathrm{~d}_{5 / 2}$ to the $4 \mathrm{~s}_{1 / 2}$. XPS data were analyzed using CASA software.[18] The purity of the oxygen used in the XPS experiments was checked on a separate UHV chamber, and no impurities were found. The detection limit for $\mathrm{CO}_{2, \mathrm{~g}}$ in the $\mathrm{O}_{2, \mathrm{~g}}$ was estimated at $0.5 \mathrm{vol} \%$.

TPD experiments were conducted on Sample D [14], which was also freshly re-polished for these experiments. Between each run, Sample D was cleaned by sputtering with $\mathrm{Ar}^{+}$at $1 \mathrm{keV}$ for 3 minutes, and annealing at $420 \mathrm{~K}$ for 20 minutes. The sample was exposed to $\mathrm{O}_{2, \mathrm{~g}}$ through a doser with a design similar to that of Winkler and Yates,[19] but with a single-aperture metal cap 
replacing the microchannel array. Based on our geometry, and the cosine distribution provided by such a doser, the pressure at the sample surface relative to the background pressure was enhanced by a factor of $7 \pm 2$.[20] During $\mathrm{O}_{2, \mathrm{~g}}$ exposure the background pressure in the TPD chamber rose to $3 \times 10^{-9} \mathrm{mbar}$, meaning that pressure at the sample was $(2.1 \pm 0.6) \times 10^{-8}$ Torr. In TPD, original software created within the LabView framework controlled the thermal program and also was interfaced with a mass spectrometer for multiplexing.

In 2 experiments, the $\mathrm{NaAu}_{2}$ (111) surface was deliberately depleted of $\mathrm{Na}$. In one case, moderate depletion was achieved with a two-cycle regimen: $\mathrm{Ar}^{+}$bombardment at $300 \mathrm{~K}$ for 10 and 20 minutes, followed by heating at $525 \mathrm{~K}$ and $700 \mathrm{~K}$ for 10 and 20 minutes, respectively. In the other case, severe depletion was achieved with a three-cycle sequence of $\mathrm{Ar}^{+}$bombardment at $300 \mathrm{~K}$ for 20,45 , and 3 minutes, followed by heating at $700 \mathrm{~K}, 750 \mathrm{~K}$, and $475 \mathrm{~K}$ for 30 , 20, and 10 minutes, respectively.

\section{Experimental Results and Interpretation.}

\subsection{Composition of the Initial Surface.}

Previously,[14] we defined a quantity $R$ as the ratio of integrated intensities for $\mathrm{Na} 1 \mathrm{~s}$ and $\mathrm{Au} 4 \mathrm{f}$ peaks (cf. Fig. 2a), corrected for the (Scofield) cross section for each photoionization event.[21] $R$ was not corrected for photoelectron attenuation or instrumental parameters. The correction for attenuation would be particularly large, since the inelastic mean free path (IMFP) of $\mathrm{Na} 1 \mathrm{~s}$ electrons is only one-third that of $\mathrm{Au} 4 \mathrm{f}$ electrons (in bulk $\mathrm{Au}$ ), i.e. 0.5 and $1.5 \mathrm{~nm}$, respectively.[22] Therefore $R$, as previously defined, is not an accurate measure of the $\mathrm{Na}: \mathrm{Au}$ composition, but it is used in this paper partly to facilitate comparisons with prior work, and partly because it reflects compositional trends with high signal-to-noise.

While the difference in sampling depth for the strong Na 1s and Au 4f XPS signals is large, this is not the case for the weaker $\mathrm{Na} 2 \mathrm{~s}$ and $\mathrm{Au} 5 \mathrm{p}_{3 / 2}$ pair. Because these differ by only 6 $\mathrm{eV}$ in binding energy (BE), they have essentially identical IMFP values. Hence they are more suitable for quantitative analysis, but precision is lower. Using these and correcting for the known cross-sections,[21] a set of values from 9 separate surface preparations results in a $\mathrm{Na}: \mathrm{Au}$ composition ratio of $0.6 \pm 0.1$, or $\mathrm{Na}_{1.2} \mathrm{Au}_{2}$, suggesting an excess of $\mathrm{Na}$ in the near surface region. (See Supplementary Material.) 


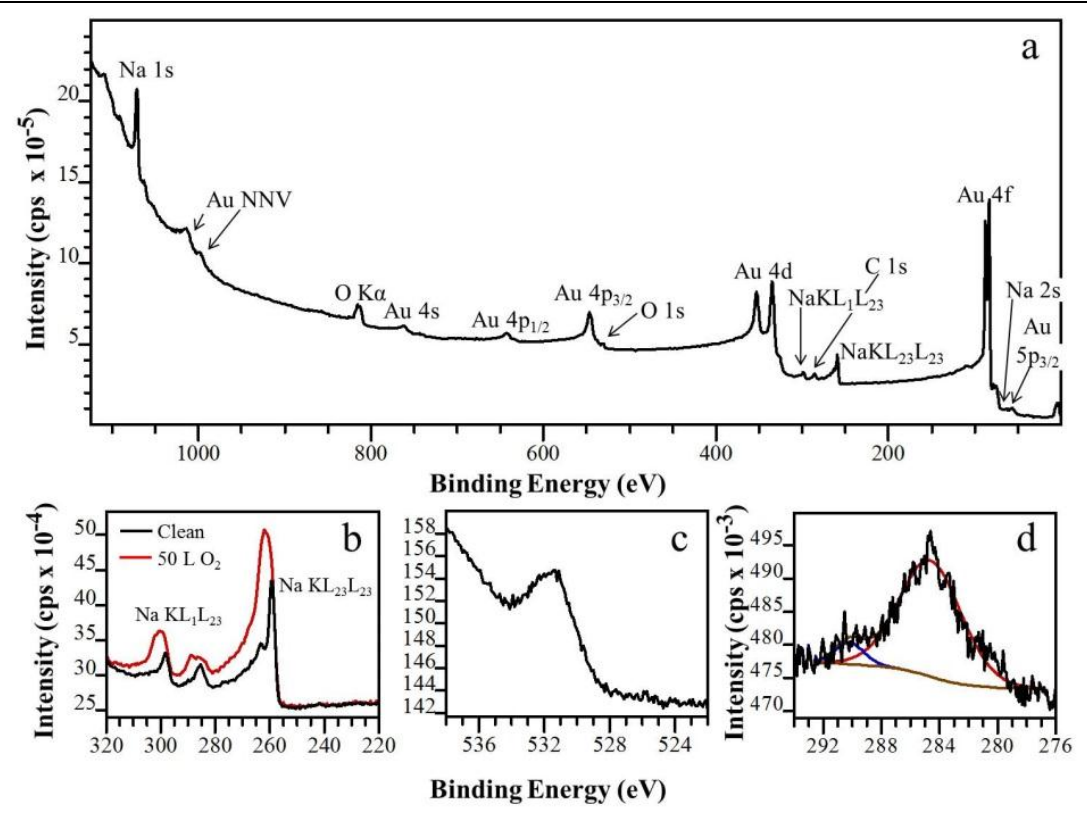

Figure 2: Photoelectron spectra for the $\mathrm{NaAu}_{2}$ clean surface. Panels (a)-(c) are acquired with a $\mathrm{Mg}$ anode, panel (d) with Al in a separate experiment. (a) Entire spectral range, 0-1125 eV, measured in $0.5 \mathrm{eV}$ steps. (b) Spectral range including $\mathrm{NaKL}_{2,3} \mathrm{~L}_{2,3}$ (ca. $260 \mathrm{eV}$ ) and $\mathrm{Na} \mathrm{KL}_{1} \mathrm{~L}_{2,3}$ (ca. $300 \mathrm{eV}$ ) lines, measured in $0.5 \mathrm{eV}$ steps. Black: Cleaned surface. Red: Surface after $50 \mathrm{~L}$ $\mathrm{O}_{2, \mathrm{~g}}$ exposure at $300 \mathrm{~K}$. (c) $\mathrm{O}$ 1s region, cleaned surface. (d) C 1s spectrum, cleaned surface. The $\mathrm{Al}$ anode is chosen in (d) to circumvent overlap with a Na Auger peak. The O K $\alpha$ peak (ca. $~ 815$ $\mathrm{eV}$ ) is due to oxidation of the $\mathrm{Mg}$ anode. The oxygen atoms on the anode are excited along with the $\mathrm{Mg}$ atoms and produce their own $\mathrm{K} \alpha \mathrm{X}$-rays, which generate a ghost spectrum at lower intensity and higher BE (shifted by $+728.7 \mathrm{eV}$ ). The most intense peaks are typically the reproduced peaks seen (i.e. Au $4 \mathrm{f}$ in this spectrum).

Other evidence supports $\mathrm{Na}$ enrichment. Even though the $\mathrm{Na} 1 \mathrm{~s}: \mathrm{Au} 4 \mathrm{f}$ ratio, $R$, should greatly underestimate the Na content for a homogeneous distribution, owing to the smaller sampling depth for Na, values of $R$ are roughly stoichiometric.[14] This indicates substantial excess $\mathrm{Na}$ within the small sampling depth of the $\mathrm{Na} 1 \mathrm{~s}$. Another indication is found in the peak/step background ratios for the Na signals compared to the Au signals. From Fig 2a, it is obvious that the inelastically-scattered background steps after the Na Auger signals (on the higher BE side) are substantially weaker than those after the Au signals. This is clear evidence that, within the depth probed, the $\mathrm{Na}$ is distributed closer to the surface, so that there is less inelastic scattering of the exiting Na photoelectrons.

Assuming, for simplicity, that the excess $\mathrm{Na}$ is segregated to the top atomic layer, and beyond that the composition is stoichiometric, the excess amount can be estimated from the standard Beer-Lambert attenuation law. Using an Effective Attenuation Length, EAL, of $1.25 \mathrm{~nm}$ (to account for a 15 to $20 \%$ elastic scattering effect correction to the IMFP [23]), and an atomic layer defined as $0.3 \mathrm{~nm}$ thick, a composition of $\mathrm{Na}_{1.5} \mathrm{Au}_{2}$ accounts for the observed $\mathrm{Na} 2 \mathrm{~s}: \mathrm{Au}$ $5 \mathrm{p}_{3 / 2}$ ratio of 0.6 . We do not, however, suggest that there is a homogeneous layer of this composition at the surface, which has a substantial fraction not representative of the bulk terminated structure (Fig 1). The excess Na could be located on mesa edges, in the valleys, or distributed in random sites on top of the mesas, which according to the LEED and XPD results 
do have the bulk terminated structure. We also note that the $\mathrm{Na} 1 \mathrm{~s}: \mathrm{Au} 4 \mathrm{f}$ ratio measurements on the 9 prepared surfaces exhibit a range of values, indicating a genuine variation in composition.

After cleaning, surfaces of $\mathrm{NaAu}_{2}$ show a small residual peak at $\mathrm{E}_{\mathrm{b}}=531.2 \pm 0.3 \mathrm{eV}$, which falls in the range expected for the O 1s BE.[24] See Fig. 2c. The KL $\mathrm{L}_{2,3}$ Auger line of Na also appears in this range with an Al Ko source, nominally at $532 \mathrm{eV} .[24,25]$ The Auger line does not fall in this region with a $\mathrm{Mg} \mathrm{K} \alpha$ source. In our experiments, the small feature is present with both X-ray sources, so it must originate at least in part from an oxygen species. Based on an analysis of relative intensities of Auger peaks with $\mathrm{Mg}$ and $\mathrm{Al}$ sources (see Supplementary Material), the Na Auger transition typically contributes 20 to $40 \%$ of the total residual intensity, with the Al source (number of data sets, N, of 4).

The nominally-clean surfaces also exhibit intensity in the $\mathrm{C} 1 \mathrm{~s}$ region. As shown in Fig. $2 \mathrm{~d}$, there are two peaks. The larger, at $284-285 \mathrm{eV}$, is in the range associated with $\mathrm{C}-\mathrm{C}$ bonded species, and the smaller, at $289-290 \mathrm{eV}$, is associated with $\mathrm{C}-\mathrm{O}$ double bonds. The large negative heat of formation of sodium carbonate, $-1130 \mathrm{~kJ} / \mathrm{mol}$, [26] makes carbonate a likely assignment for the latter. For comparison, the $\mathrm{C} 1 \mathrm{~s}$ position falls at $289.0 \mathrm{eV}$ for carbonate on $\mathrm{Ni}(111),[27]$ and at $289.3 \mathrm{eV}$ for bulk $\mathrm{Na}_{2} \mathrm{CO}_{3}$. [28] The carbonate peak is convolved with the $\mathrm{KL}_{1} \mathrm{~L}_{2,3} \mathrm{Na}$ Auger line for a $\mathrm{Mg} \mathrm{K \alpha}$ source, but not for Al.[25] It is notable that although the carbonate $\mathrm{C} 1 \mathrm{~s}$ peak is small, it correlates with a much stronger $\mathrm{O} 1 \mathrm{~s}$ peak, partly because of the 3:1 stoichiometry, and partly because the photoionization cross-section of $\mathrm{O} 1 \mathrm{~s}$ is 2.9 times that of $\mathrm{C}$ $1 \mathrm{~s},[21]$ leading to intensity amplification by a factor of 8.7. Throughout this paper, we assume that the $289-290 \mathrm{eV}$ peak is carbonate, and use the factor of 8.7 to deduce the fraction of associated $\mathrm{O} 1 \mathrm{~s}$ intensity. For the initial surface, carbonate then accounts for $20-30 \%$ of the oxygen-derived (non-Auger) $\mathrm{O} 1 \mathrm{~s}$ signal $(\mathrm{N}=2)$. The remainder is reasonably attributed to oxygen dissolved in the bulk, supported by data in Sec. 3.3 below.

\subsection{Oxygen Exposure at $300 \mathrm{~K}$.}

Focusing first on the $\mathrm{O} 1 \mathrm{~s}$ spectral region, exposure to oxygen causes the residual peak to intensify. It also produces peaks at 1 or 2 new positions in the $\mathrm{O} 1 \mathrm{~s}$ region, depending on the $\mathrm{X}$ ray source, as shown in Fig. 3. The 3 peaks are labeled A, B, C in order of decreasing (apparent) BE. Their areas and positions are determined via deconvolution, as illustrated in Fig. $3 \mathrm{a}$ and Fig. 3d. Arguments for individual assignments follow.

Peak A, at $535 \pm 0.2 \mathrm{eV}$, is observed only with the Al source, and must therefore be the $\mathrm{Na} \mathrm{KL}_{1} \mathrm{~L}_{2,3}$ Auger peak. It apparently shifts upward from the residual position upon oxygen exposure (cf. Sec. 3.1). This is substantiated by shifts observed for other Na Auger lines. For example, in Fig. $2 b$ the $\mathrm{KL}_{2,3} \mathrm{~L}_{2,3}$ line moves upward by about $3 \mathrm{eV}$ after $50 \mathrm{~L} \mathrm{O}_{2}$ exposure. The intensification of Peak A with increasing oxygen exposure, evident in Fig. 3b, reflects increasing $\mathrm{Na}$ surface concentration as will be discussed in the following material. 

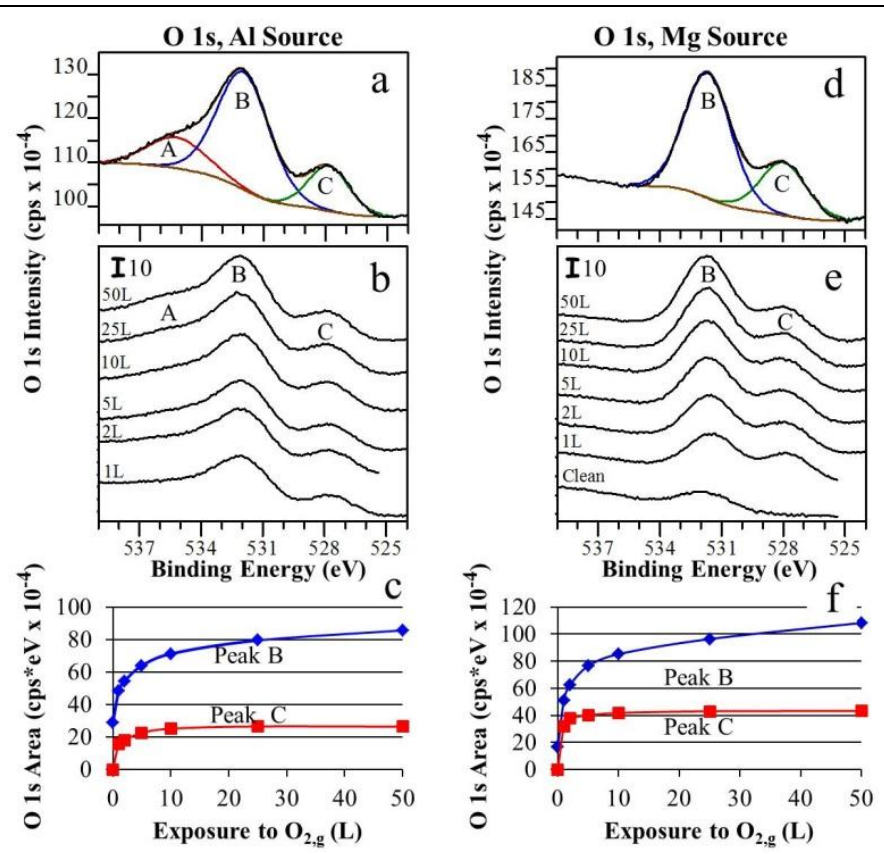

Figure 3: Photoelectron spectra in the $\mathrm{O}$ 1s region, for two sequences of oxygen exposures at 300 K. Data in (a), (b), and (c) were acquired with an Al Ka X-ray source. Data in (d), (e), and (f) were acquired with a Mg K $\alpha$ X-ray source in an entirely separate experiment. In (b) and (e), the curves are displaced vertically to minimize overlap. The intensity, in units of cps $x 10^{-4}$, can be derived using the scale bar. (a) Spectrum obtained after $50 \mathrm{~L}$ exposure, deconvoluted into three peaks. (b) Sequence of spectra following exposures to $1 \mathrm{~L}$ to $50 \mathrm{~L}$ (c) Integrated areas of Peaks B and $\mathrm{C}$ as a function of exposure. (d) Spectrum obtained after $50 \mathrm{~L}$ exposure, deconvoluted into two peaks. (e) Sequence of spectra following exposures to $1 \mathrm{~L}$ to $50 \mathrm{~L}$ (f) Integrated areas of Peaks B and C as a function of exposure. Y-axis "cps" units are defined as counts per second.

Peaks $\mathrm{B}$ and $\mathrm{C}$, at $531.5 \pm 0.4 \mathrm{eV}$ and $527.9 \pm 0.2 \mathrm{eV}$ respectively, represent oxygen species that grow with increasing oxygen exposure, developing roughly in parallel as shown by Fig. 3c and Fig. 3f. Close inspection reveals a difference, however: Peak $\mathrm{C}$ reaches a plateau at $10 \mathrm{~L}$, whereas Peak B continues to grow steadily beyond this exposure. This different evolution indicates that these two peaks do not have a common origin. The BE of Peak B is compatible with carbonate and, as shown below, carbonate contributes a substantial fraction of its total intensity but not all. The BE of Peak $\mathrm{C}$ is much lower than normally observed for atomic oxygen adsorbed on transition metal surfaces, suggesting an electron-rich oxygen atom in an ionic bond; sodium oxide is an obvious candidate. For comparison, the $\mathrm{O} 1 \mathrm{~s} \mathrm{BE}$ for an oxidized surface of bulk $\mathrm{Na}$ falls at $529.6 \mathrm{eV}$.[25]

Angle-resolved XPS is not generally informative in this system. Most often, trends as a function of $\theta$ are small and irreproducible. This may be due to the intrinsic roughness of the surface, illustrated in the STM images of Fig. 1. However, there is one trend that is reproducible and relatively strong. Fig. 4 shows the relative contributions of Peaks $\mathrm{B}$ and $\mathrm{C}$ to the total $\mathrm{O} 1 \mathrm{~s}$ intensity, after $50 \mathrm{~L}$ exposure at $300 \mathrm{~K}$, at $\theta=0^{\circ}, 60^{\circ}$, and $80^{\circ}$ with a $\mathrm{Mg}$ source. Two separate experiments are shown, to illustrate the degree of consistency. Peak B contributes a greater fraction of the total $\mathrm{O} 1 \mathrm{~s}$ intensity as the emission angle becomes more shallow (more surfacesensitive). From this, we conclude that Peak B represents species that are more localized at the surface, whereas Peak $\mathrm{C}$ has contributions from deeper in the bulk. 


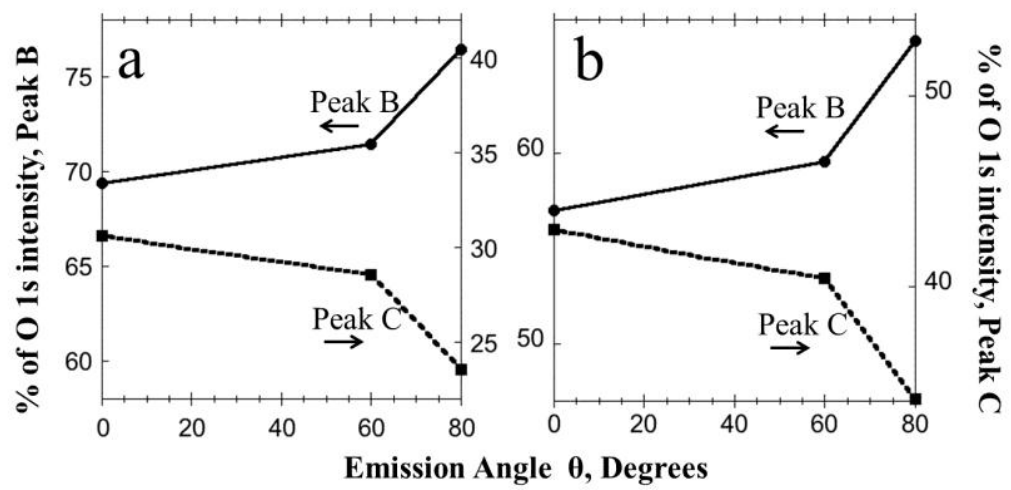

Figure 4: Percent of total O 1s intensity for Peaks B and C, as a function of emission angle, following a $50 \mathrm{~L}$ exposure at $300 \mathrm{~K}$. The X-ray source is $\mathrm{Mg} \mathrm{K \alpha}$. Each vertical axis spans $20 \%$. (a) and (b) represent two separate experiments, and are shown to indicate reproducibility.

Oxygen adsorption is accompanied by changes in the $\mathrm{Na}$, Au, and $\mathrm{C}$ signals. Fig. 5 shows that the $\mathrm{Na} 1 \mathrm{~s}$ line intensifies, while the Au 4f line weakens. (Neither has any overlap with lines of other elements in the system.) These changes are also represented as a strong increase in $R$, shown in Fig. 5c. After exposure to $50 \mathrm{~L} \mathrm{O}_{2, \mathrm{~g}}$ at $300 \mathrm{~K}, R$ increases by an average factor of $2.6 \pm$ $0.6(\mathrm{~N}=8)$. This means that $\mathrm{Na}$ becomes much more abundant, concurrent with oxygen adsorption. At the same time, the carbonate peak grows as shown in Fig. 5d. At 50 L, carbonate accounts for half of the oxygen species represented by Peak B in the experiment of Fig. 2a-c.
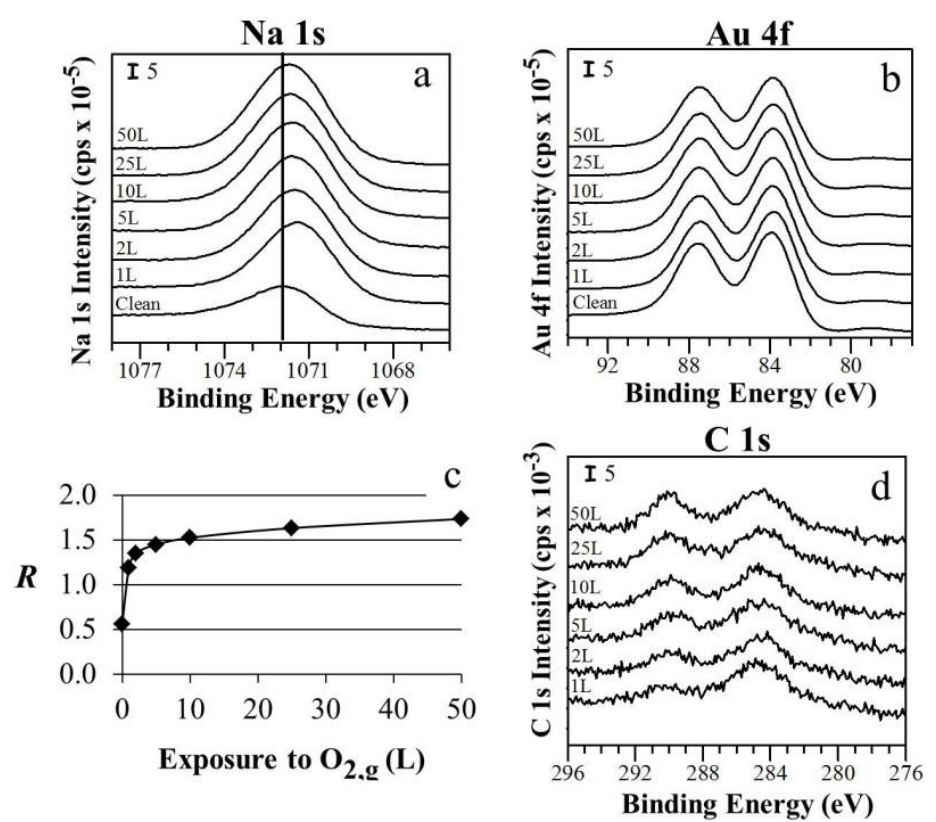

Figure 5: $\mathrm{Na} 1 \mathrm{~s}, \mathrm{Au} 4 \mathrm{f}$, and $\mathrm{C}$ 1s photoelectron peaks for experiments in which the surface was exposed to oxygen sequentially from 1 to $50 \mathrm{~L}$ at $300 \mathrm{~K}$. The $\mathrm{X}$-ray anode is $\mathrm{Mg}$ in the experiment of panels a-c, and $\mathrm{Al}$ in the experiment of panel $\mathrm{d}$. In (a), (b), and (d), the curves are displaced vertically to minimize overlap. The intensity, in units of cps x $10^{-5}$ or cps x $10^{-3}$ can be derived using the scale bar. (a) Na 1s. (b) Au 4f. (c) $R$ vs. oxygen exposure. (d) C 1s. 
The intensity of Peak B depends on the conditions of exposure, being reduced by $1 / 3$ if exposure is carried out in a single step rather than sequentially. This is almost entirely due to a reduction in the quantity of carbonate-oxygen. Possible sources of carbon for carbonate include contamination from the X-ray anode, adventitious carbon represented by the $\mathrm{C} 1 \mathrm{~s}$ peak at 284$285 \mathrm{eV}$, and diffusion of carbon from the bulk sample in concert with $\mathrm{Na}$. We do not consider $\mathrm{CO}_{\mathrm{g}}$ or $\mathrm{CO}_{2, \mathrm{~g}}$ as likely candidates, since they were undetectable in the $\mathrm{O}_{2, \mathrm{~g}}$. Consistently, the amount of adventitious carbon declines upon oxygen exposure, indicating that this may indeed contribute, although there is not a quantitative correlation between the magnitude of this decrease and carbonate increase. But also, the fact that carbonate is higher in the sequential experiments could indicate an origin in contamination from the X-ray source. In short, we are unable at present to determine the carbonate's source(s).

Finally, in Fig. 6 we show the XPD patterns observed after $50 \mathrm{~L} \mathrm{O}_{2, \mathrm{~g}}$ exposure at $300 \mathrm{~K}$. The structure in the Na 1s pattern for the initial surface (Fig. 1c) is gone, replaced by a diffuse background exhibiting broad three-fold symmetry. The O 1s XPD is similar. The Au 4f pattern is still evident, but with higher background. The Au structure is probed more deeply than Na due to its larger IMFP (cf. Sec. 3.1), so these XPD data likely mean that the top few layers become disordered, while the bulk structure is retained deeper below the surface.

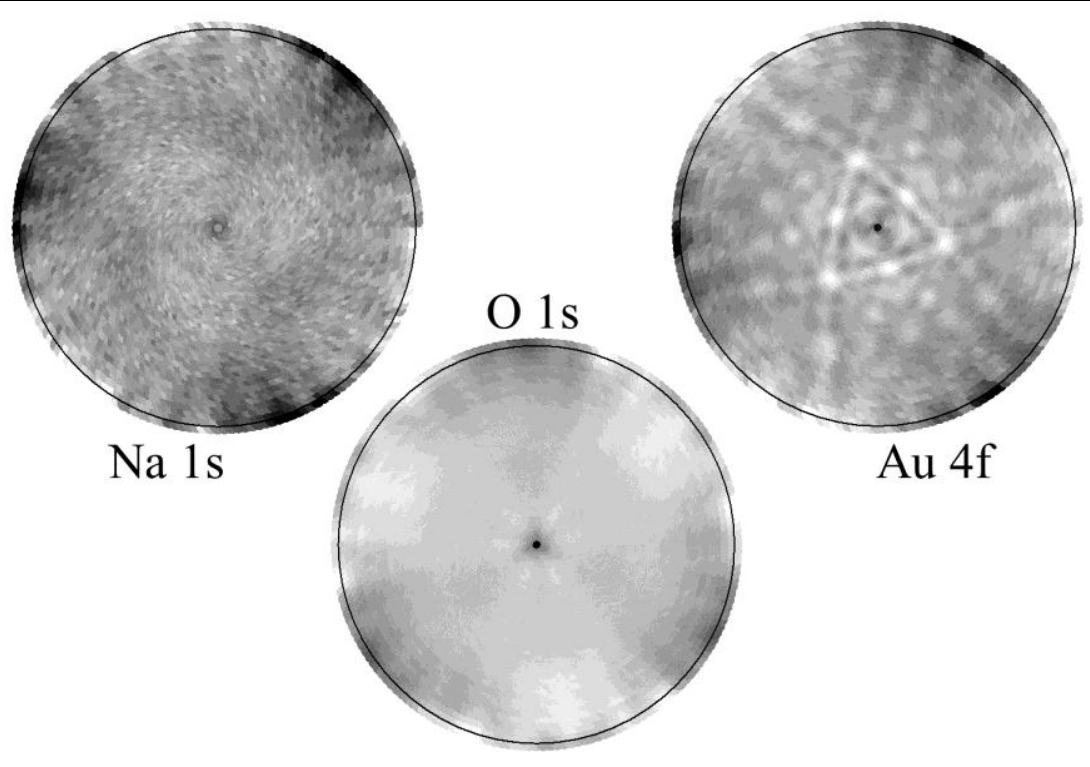

Figure 6: XPD patterns after $50 \mathrm{~L} \mathrm{O}_{2, \mathrm{~g}}$ exposure at $300 \mathrm{~K}$. The X-ray anode is $\mathrm{Al}$.

\subsection{Effects of Heating to Temperatures Below and Above the Na Desorption Onset.}

Experiments in which the surface is exposed to $50 \mathrm{~L} \mathrm{O}_{2, \mathrm{~g}}$ at $300 \mathrm{~K}$, then annealed at 425 $\mathrm{K}$ and $475 \mathrm{~K}$, are informative. These two temperatures are chosen because they are slightly below and slightly above the onset of Na desorption, respectively.[14] Peaks B and C respond differently to this thermal treatment, as illustrated in Fig. 7a and Fig. 7b. 

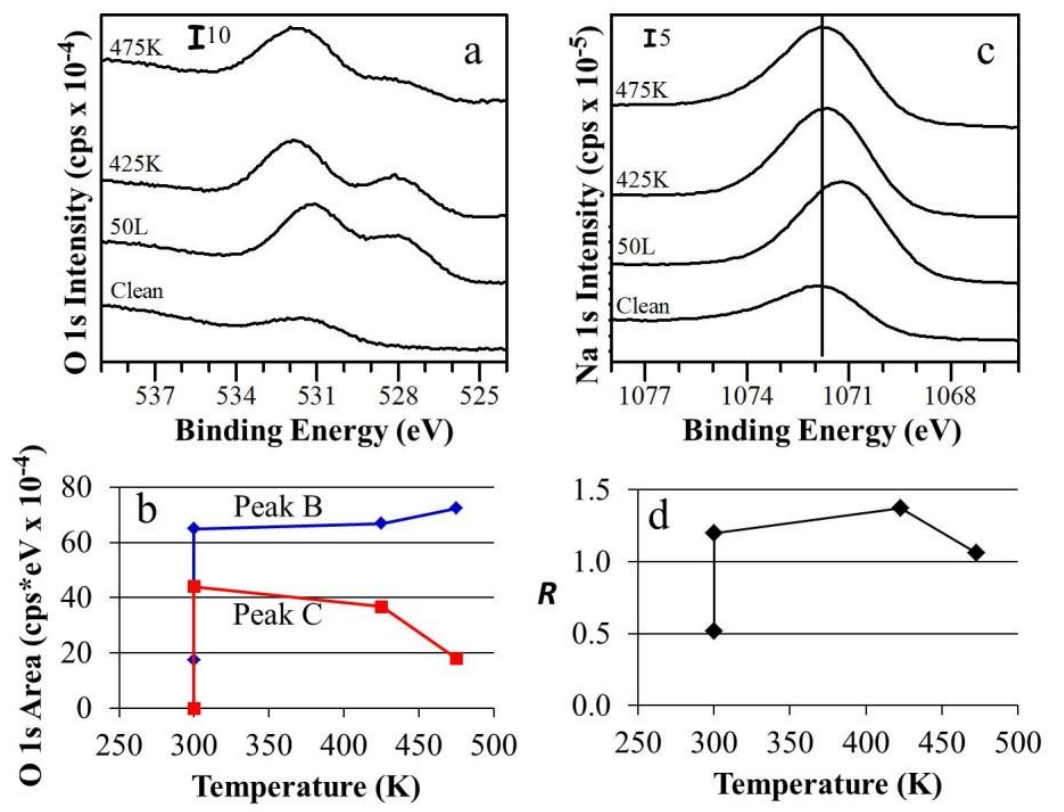

Figure 7: Result of exposing a surface to $50 \mathrm{~L} \mathrm{O}_{2, \mathrm{~g}}$ at $300 \mathrm{~K}$, then annealing sequentially to 425 $\mathrm{K}$ and $475 \mathrm{~K}$. The X-ray source is $\mathrm{Mg} \mathrm{K \alpha}$. In (a) and (c), the curves are displaced vertically to minimize overlap. The intensity, in units of cps $x 10^{-4}$, can be derived using the scale bar. (a) $\mathrm{O}$ 1s spectral region. (b) Integrated areas of Peaks B and C. In each case, the lower point at $300 \mathrm{~K}$ represents the clean surface, and the upper point is obtained after $50 \mathrm{~L}$ exposure to oxygen. (c) ) $\mathrm{Na}$ 1s spectra for the same sequence as in panel (a). (d) $R$ vs temperature. The lower point at 300 $\mathrm{K}$ represents the clean surface, and the upper point is obtained after $50 \mathrm{~L}$ exposure to oxygen.

We have considered the possibility that Peak B (at higher BE) represents molecular oxygen, and the other peak represents atomic oxygen. However, if Peak B were molecular oxygen, its intensity would decrease with heating, due to dissociation. (Desorption can be ruled out based on TPD data presented below.) Its behavior rules out this assignment.

Heating also affects the intensities of the $\mathrm{Au} 4 \mathrm{f}$ and $\mathrm{Na} 1 \mathrm{~s}$ peaks, and consequently affects the value of $R$. The Na 1s spectra, and $R$, are shown in Fig. 7c and Fig. 7d. (The Au 4f spectra are omitted, since only their intensity changes measurably, and this change is captured in $R$.) Between $300 \mathrm{~K}$ and $425 \mathrm{~K}$, the Na content increases slightly, but between $425 \mathrm{~K}$ and $475 \mathrm{~K}$, it decreases. We attribute these changes in $\mathrm{Na}$ and Au concentration to activated diffusion of $\mathrm{Na}$ from the bulk toward the surface at $425 \mathrm{~K}$, followed by loss of $\mathrm{Na}$ due to desorption at $475 \mathrm{~K}$. At the same time, the intensity of the carbonate $\mathrm{C}$ 1s signal (not shown) is unaffected by heating, indicating that carbonate does not contribute to the observed changes. Anhydrous sodium carbonate is reportedly stable in air up to $800 \mathrm{~K}$.[29]

TPD adds more insight. Fig. 8a illustrates the intensity of the signal at a mass-to-charge ratio of $\mathrm{m} / \mathrm{e}=23$, corresponding to the apparent partial pressure of $\mathrm{Na}$, as a function of temperature. The curves overlap, i.e. oxygen has no effect on $\mathrm{Na}$ desorption. At this heating rate, $6.0 \mathrm{~K} / \mathrm{s}$, Na begins to desorb at about $480 \mathrm{~K}$. However, there would certainly be significant desorption if the sample were held at $475 \mathrm{~K}$ for extended periods, like the 20 minute anneals in the experiments of Fig. 7. Fig. 8b demonstrates that the partial pressures of $\mathrm{m} / \mathrm{e}=32 \mathrm{and} \mathrm{m} / \mathrm{e}=39$, corresponding to $\mathrm{O}_{2}$ and $\mathrm{NaO}$, respectively, are invariant with temperature in the same temperature range. In other words, there is no evidence for desorption of $\mathrm{O}_{2}$ or $\mathrm{NaO}$. This means 
that as the sample is heated, the loss of oxygen indicated in XPS must be due to bulk dissolution, hence explaining part of the residual peak on the as-prepared surface.
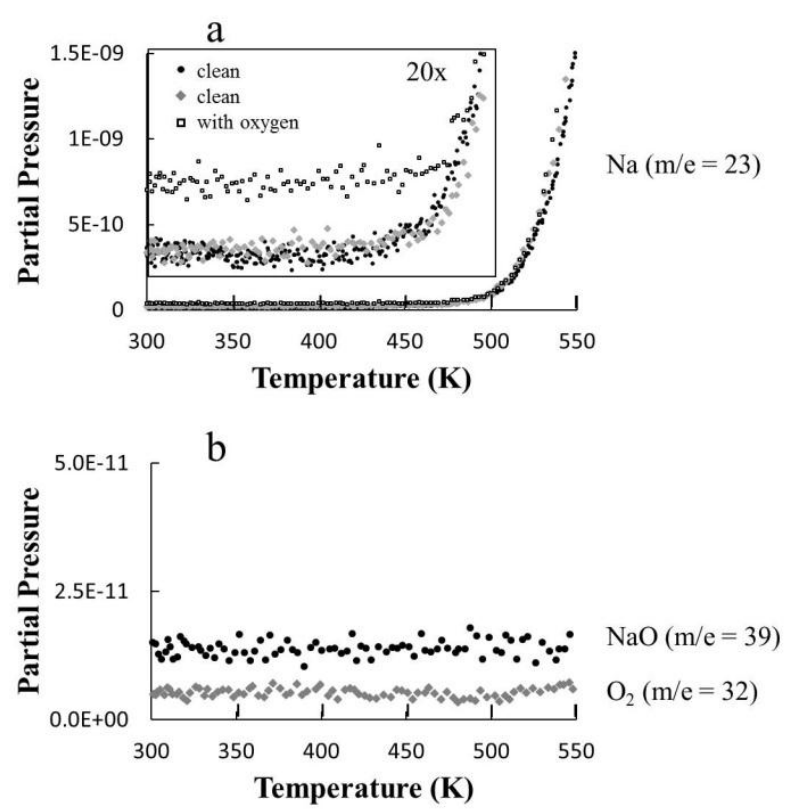

Figure 8: Results of TPD for clean surfaces and after $25 \mathrm{~L} \mathrm{O}_{2, \mathrm{~g}}$ exposure at $300 \mathrm{~K}$. The heating rate is linear at $6.0 \mathrm{~K} / \mathrm{s}$, from $350 \mathrm{~K}$ onward. The partial pressure is given in units of Torr. (a) Na desorption $(\mathrm{m} / \mathrm{e}=32)$ from cleaned surfaces and after oxygen exposure. (b) $\mathrm{NaO}(\mathrm{m} / \mathrm{e}=39)$ and $\mathrm{O}_{2}(\mathrm{~m} / \mathrm{e}=32)$ desorption after oxygen exposure.

All of this information forms a basis for the following model. Peak $\mathrm{C}$ originates from oxygen bonded only or mainly to $\mathrm{Na}$, located in the surface and near-surface region. At $300 \mathrm{~K}$, it grows in a self-limiting process, leading to saturation of Peak $\mathrm{C}$ as a function of oxygen exposure. If this sample is heated to $425 \mathrm{~K}$, the reaction can proceed a little further; more $\mathrm{Na}$ moves upward (toward the surface), causing $R$ to increase slightly. However, this process must result purely from equilibration, since no new oxygen is available from adsorption during this experiment. At $475 \mathrm{~K}$, the sample loses some $\mathrm{Na}$ via desorption, causing a decrease in $R$, and a further decrease in Peak C intensity. On the other hand, Peak B originates partly from carbonate, and partly from adsorbed atomic oxygen in an environment that is influenced by both $\mathrm{Na}$ and $\mathrm{Au}$. We do not associate Peak B with oxygen interacting only with Au atoms, since oxygen is not stable on macroscopic, pure Au surfaces.[30-33]

If this model is correct, then two predictions can be made. First, oxygen exposure at 425 $\mathrm{K}$ should favor Peak C over Peak B, by allowing the O-Na reaction to occur more effectively during oxygen adsorption. This should be accompanied by a stronger increase in $R$ than the 2.6fold increase upon simply heating from $300 \mathrm{~K}$ to $425 \mathrm{~K}$. Secondly, a Na-depleted surface should ad/absorb less total oxygen, and Peak $\mathrm{C}$ should be especially attenuated. We therefore test the model by performing these specific experiments.

\subsection{Oxygen Adsorption at $425 \mathrm{~K}$.}

Exposing the surface to $100 \mathrm{~L} \mathrm{O}_{2, \mathrm{~g}}$ at $425 \mathrm{~K}$ yields the $\mathrm{O}$ 1s spectrum shown in Fig. 9a. Compared to exposure at $300 \mathrm{~K}$ (Fig. 3), the intensities of Peaks B and C are reversed, i.e. Peak $\mathrm{C}$ is more intense than Peak B. Furthermore, $R$ increases from 0.48 for the initial clean surface, 
to 4.4 after oxygen exposure-almost a 10-fold change, much higher than the factor of 2.6 at 300 $\mathrm{K}$. This indicates much stronger surface segregation of $\mathrm{Na}$ when the sample is exposed to $\mathrm{O}_{2, \mathrm{~g}}$ at $425 \mathrm{~K}$ than at $300 \mathrm{~K}$. Both of these changes are consistent with predictions from Sec. 3.3.
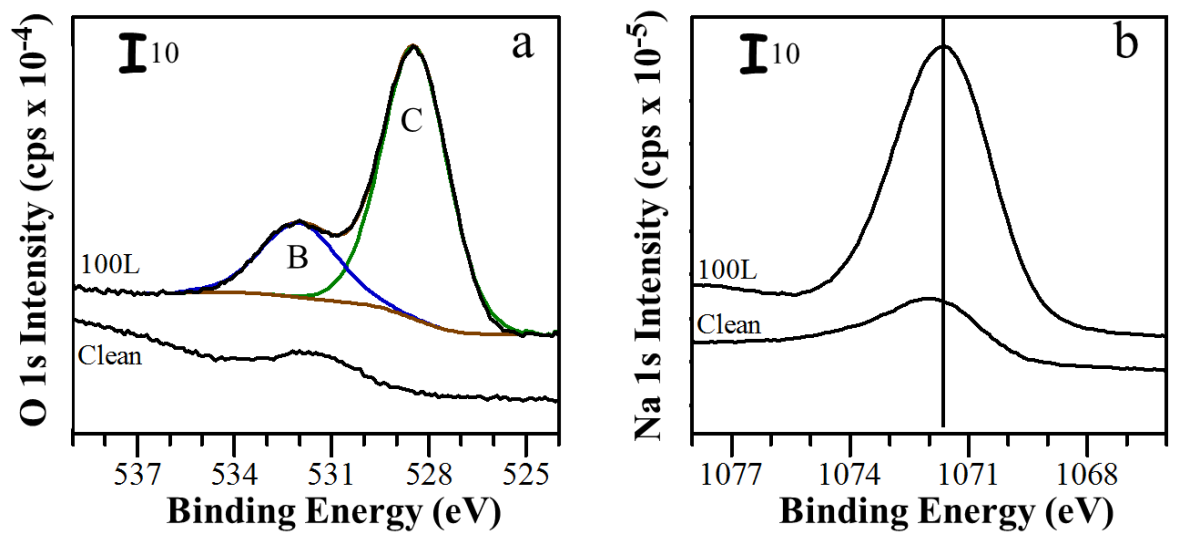

Figure 9: Result of exposing a surface to $100 \mathrm{~L} \mathrm{O}_{2, \mathrm{~g}}$ at $425 \mathrm{~K}$. The $\mathrm{X}$-ray source is $\mathrm{Mg} \mathrm{K \alpha}$. The curves are displaced vertically to minimize overlap. The intensity, in units of cps $\times 10^{-4}$, can be derived using the scale bar. (a) $\mathrm{O} 1 \mathrm{~s}$ spectral region, with clean surface for reference and $100 \mathrm{~L}$ exposure deconvoluted into two peaks. (b) $\mathrm{Na} 1 \mathrm{~s}$ spectral region for the same sequence as in panel (a).

\subsection{Oxygen Adsorption on Na-depleted Surfaces at $300 \mathrm{~K}$.}

As described in Sec. 2, we deliberately removed $\mathrm{Na}$ from the surface via extended ion bombardment at $300 \mathrm{~K}$, followed by annealing at temperatures as high as $750 \mathrm{~K}$. In this way, surfaces with initial values $R_{0}=0.30$ and $R_{0}=0.09$ were generated. $\left(R_{0} \leq 0.4\right.$ indicates that an irreversible transformation to crystalline Au has begun in the surface and near-surface region.[14]) Subsequent exposure to $50 \mathrm{~L} \mathrm{O}_{2, \mathrm{~g}}$ in a single step produced the results shown in Fig. 10. Under these conditions, there is no trace of Peak $\mathrm{C}$ (even in deconvoluted spectra). This validates the expectation that Peak $\mathrm{C}$ is more strongly dependent on $\mathrm{Na}$ concentration than Peak B.
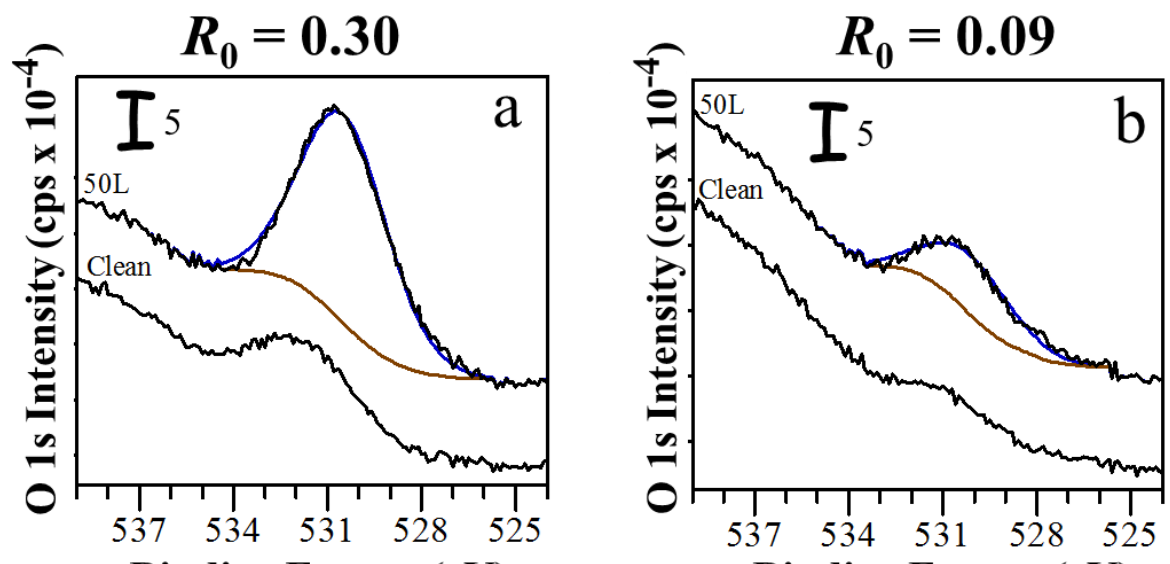

Binding Energy (eV)

Binding Energy (eV)

Figure 10: Results of exposing two sodium-depleted surfaces to $50 \mathrm{~L} \mathrm{O}_{2, \mathrm{~g}}$ in a single step at 300 $\mathrm{K}$. The X-ray source is $\mathrm{Mg} \mathrm{K \alpha}$. The curves are displaced vertically to minimize overlap. The intensity, in units of cps x $10^{-4}$, can be derived using the scale bar. (a) $R_{0}=0.30$. O 1 s spectral 
region. Bottom and top curves are before and after exposure, respectively. (b) $R_{0}=0.09$. O $1 \mathrm{~s}$ spectral region. Bottom and top curves are before and after exposure, respectively.

The total amount of adsorbed oxygen decreases with decreasing $R_{0}$ (decreasing initial $\mathrm{Na}$ content), as shown by comparing Fig. 10a with Fig. 10b. To illustrate this further, the $\mathrm{O} 1 \mathrm{~s}$ area is plotted vs. $R_{0}$ in Fig. 11. The data point at far left represents a normal $\mathrm{NaAu}_{2}$ surface. Comparing this point with the two from Na-depleted surfaces (farther right), shows a steady decrease and ultimately a ten-fold reduction in the total amount of adsorbed oxygen. This is also in agreement with the prediction.

Another feature is that oxygen adsorption on depleted surfaces produces only small changes in $R$. For the marginally depleted surface, $R$ increases from 0.30 to 0.48 , a factor of 1.6. For the heavily depleted surface, $R$ increases from 0.09 to 0.12 , a factor of 1.3 . These are much smaller than the factors of 2.6 and 10 for non-depleted surfaces at $300 \mathrm{~K}$ and $425 \mathrm{~K}$, respectively. This result is reasonable since, on the depleted surfaces, there is less Na available in the nearsurface region to segregate upward in response to oxygen adsorption.

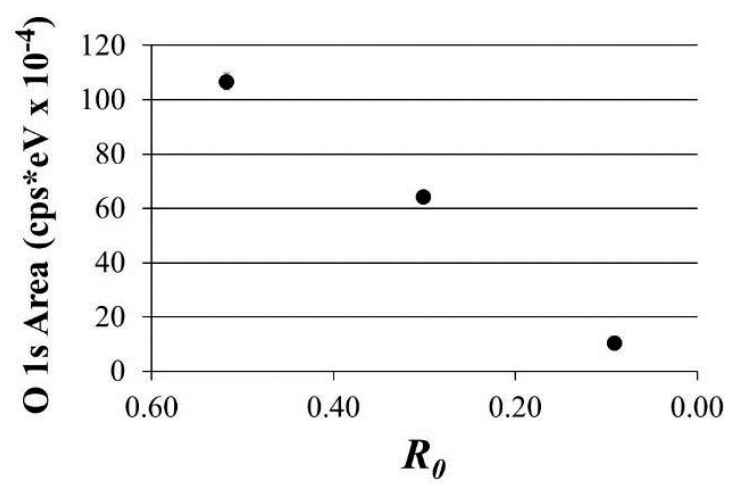

Figure 11: $\mathrm{O}$ 1s integrated areas vs. $R_{0}$ values after exposing a surface to $50 \mathrm{~L} \mathrm{O}_{2, \mathrm{~g}}$. The point at $0.52 R_{0}$ is an average of two one-step exposures with the $\mathrm{Mg}$ anode. Error bars are barely larger than the data symbol. The remaining points each represent one exposure with the $\mathrm{Mg}$ anode, corresponding to Fig. 10.

\section{Discussion.}

The data show that there are two main $\mathrm{O} 1 \mathrm{~s}$ lines associated with adsorbed oxygen. The one at low BE, Peak C, represents a sodium oxide(-like) species that is distributed in the surface and near-surface region. The one at higher BE, Peak B, has contributions from carbonate and from a type of adsorbed oxygen that interacts both with $\mathrm{Na}$ and $\mathrm{Au}$.

The XPD patterns show that these species cannot be interpreted in terms of the bulk termination. Nonetheless, earlier calculations for atomic oxygen adsorbed on such a surface[12] are informative. Relevant adsorption sites are shown in Fig. 12. Two of these are most favorable for atomic oxygen, with equal adsorption energies of $\mathrm{E}_{\mathrm{ad}}=-0.60 \mathrm{eV}$. The first site is labeled fcc-Na. Here the oxygen adatom interacts with three Au atoms in the top layer and one $\mathrm{Na}$ atom beneath. If every such site is filled, then oxygen coverage in atomic monolayers (ML) is $1 / 3$, where unity means one $\mathrm{O}$ atom per $\mathrm{Au}$ atom in the surface layer. The stabilization imparted by 
underlying $\mathrm{Na}$ is clear from comparison with the hcp-Au site, for which $\mathrm{E}_{\mathrm{ad}}=-0.18 \mathrm{eV}$. The second site is the Na-bridge site (Fig. 12), where oxygen bridges $2 \mathrm{Au}$ atoms and also interacts with a pop-out Na. If all such sites are filled the coverage is again 1/3 ML. Therefore, DFT points to the importance of mixed $\mathrm{Na}-\mathrm{Au}$ sites for oxygen adsorption, which agrees with experiment.

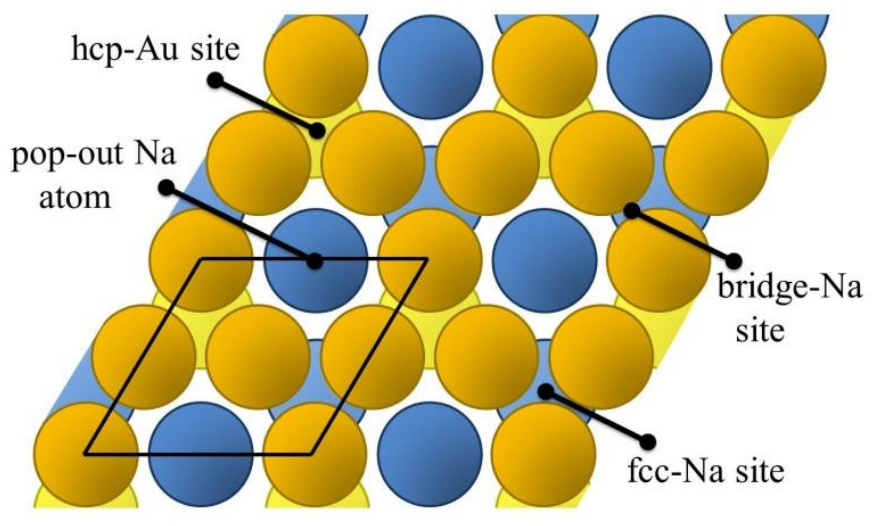

Figure 12: Atoms in the top 4 planes in $\mathrm{NaAu}_{2}(111)$. Atoms and planes are identified as follows, with respect to a $\mathrm{z}$-axis perpendicular to the surface plane: Dark yellow, Au atoms at $\mathrm{z}=0$; dark blue, $\mathrm{Na}$ at $\mathrm{z}=-0.143 \mathrm{~nm}$; yellow, Au at $\mathrm{z}=-0.225 \mathrm{~nm}$; and light blue, $\mathrm{Na}$ at $\mathrm{z}=-0.307 \mathrm{~nm}$.

It is possible to estimate the amount of oxygen present in Peak B, as follows. The XPS intensity, $\mathrm{I}_{\mathrm{d}}$, originating from a depth, $\mathrm{d}$, is given by

$$
I_{d}=I_{0}\left(1-\mathrm{e}^{-d /\left(E A L^{*} \cos \theta\right)}\right)
$$

Here $I_{0}$ is the integrated intensity from infinite depth, i.e. from the bulk material. To calculate the fraction of $\mathrm{Au}$ signal originating from the top atomic layer of the clean surface, an EAL of 1.25 $\mathrm{nm}$ is used (as justified in Sec. 3.1, for a Mg anode) and an atomic layer thickness of $0.3 \mathrm{~nm}$ is assumed. The emission angle $\theta$ is $60^{\circ}$. Substituting in the equation above gives an $I_{d}$ of 0.37 , that is, $37 \%$ of the $\mathrm{Au}$ signal originates from the outermost layer of Au. The oxygen coverage then is simply the observed $\mathrm{O} 1 \mathrm{~s}$ intensity after adsorption, relative to $37 \%$ of the observed Au signal of the clean surface, after correcting both intensities for their relative photoionization crosssections. (An underlying assumption is that all oxygen in Peak B is at the surface, as supported by the angle-resolved XPS.) The experimental ratio of $\mathrm{O} 1 \mathrm{~s}: \mathrm{Au} 4 \mathrm{f}$ intensities with the Mg anode, for sequential exposures to $50 \mathrm{~L}$, is $0.085(\mathrm{~N}=2)$. Correcting for the known relative crosssections of 2.85 and 17.5 , respectively,[21] the ratio becomes 0.52 , so the oxygen coverage is $0.52 / 0.37=1.4 \mathrm{ML}$. Half of this is carbonate per Sec. 3.2, leaving 0.7 ML of Peak B as oxygen adsorbed at $\mathrm{Na}-\mathrm{Au}$ sites. This is twice the coverage predicted for an ideal $\mathrm{NaAu}_{2}$ surface. The disordering that accompanies oxygen adsorption may be a restructuring that optimizes local NaAu-oxygen bonding, producing higher oxygen coverage than could be achieved on the ideal surface.

Turning now to the oxygen in Peak $\mathrm{C}$, its development is accompanied by diffusion of $\mathrm{Na}$ from the bulk toward the surface. This diffusion is more facile at $425 \mathrm{~K}$ than at $300 \mathrm{~K}$, leading to 
a deeper and more extensive sodium oxide. (Inward diffusion of oxygen may also be important.) This oxide is greatly suppressed when the initial surface is Na-depleted. Given the structural heterogeneity of the initial surface (Fig. 1), we postulate that nucleation of the oxide is also heterogeneous, probably forming initially in troughs and at edges of mesas. A schematic is shown in Fig. 13, summarizing our observations and interpretation.

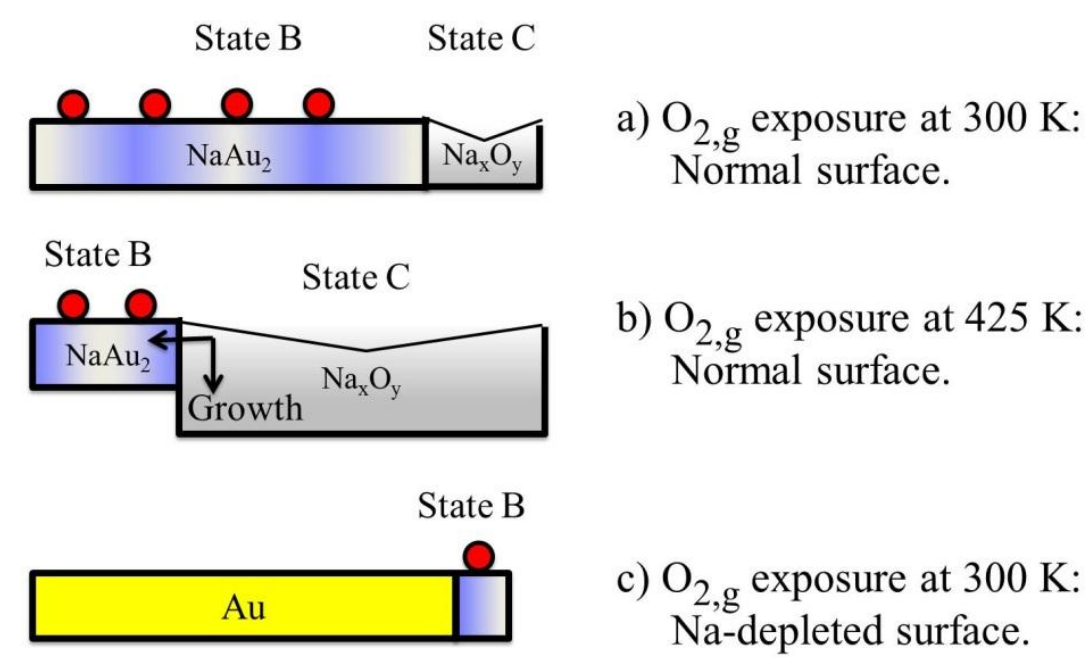

Figure 13: Model of sample surface depicting oxygen adsorption at various surface compositions and temperatures, where State $\mathrm{B}$ represents oxygen interacting with $\mathrm{NaAu}_{2}$, and State $\mathrm{C}$ represents $\mathrm{Na}_{\mathrm{x}} \mathrm{O}_{\mathrm{y}}$. The angled shape associated with $\mathrm{Na}_{\mathrm{x}} \mathrm{O}_{\mathrm{y}}$ is meant to suggest that they may be preferentially associated with troughs and edges of mesas. (a) Normal initial surface with $\mathrm{O}_{2, \mathrm{~g}}$ exposure at $300 \mathrm{~K}$. (b) Normal initial surface with $\mathrm{O}_{2, \mathrm{~g}}$ exposure at $425 \mathrm{~K}$. (c) Na-depleted surface with $\mathrm{O}_{2, \mathrm{~g}}$ exposure at $300 \mathrm{~K}$.

Formation of sodium oxide is reasonable from a thermodynamic perspective. The formation enthalpy of $\mathrm{NaAu}_{2}$ is $-99 \mathrm{~kJ} / \mathrm{mol}$ from experiment,[34] whereas the corresponding values for oxides of sodium are much more negative [26]: -263 for $\mathrm{NaO}_{2},-409$ for $\mathrm{Na}_{2} \mathrm{O}$, and 505 for $\mathrm{Na}_{2} \mathrm{O}_{2}$, all in $\mathrm{kJ} / \mathrm{mol}$. The surface oxide may well be a mixture or a progression of these, depending upon relative availability of $\mathrm{Na}$ and $\mathrm{O}$.

Finally, we consider some implications for understanding the catalytic activity of powdered or dispersed $\mathrm{NaAu}_{2}$. Our data show that oxygen disrupts the surface structure of $\mathrm{NaAu}_{2}(111)$, implying that the bulk termination is not a good model for the majority of a real surface, at least not under reaction conditions where oxygen can accumulate. Second, the data show that sodium oxide - and sodium carbonate - form readily in oxygen-rich environments, and so may influence catalytic reactions. Third, there is evidence for an atomic oxygen species that is stabilized by interaction both with $\mathrm{Na}$ and $\mathrm{Au}$, consistent with the stability of atomic oxygen at such mixed sites in Ref. [12]. It is possible that the formation of sodium oxide and carbonate entails the production of under-coordinated Au sites on the surface. It has been shown, both experimentally and theoretically, that under-coordinated Au sites can greatly increase the catalytic activity of gold surfaces. [35, 36]

\section{Conclusions.}


XPS and AES analysis of the as-prepared surface reveals enrichment in Na. The excess $\mathrm{Na}$ is probably distributed heterogeneously on the surface, in light of the structural heterogeneity. XPS also reveals residual oxygen and carbon. After oxygen exposure, there are two oxygenderived XPS peaks. From angle-resolved data, the one at higher BE represents a species that is surface-localized, whereas the other is distributed through the surface and near-surface region. The surface-localized state is a combination of adventitious carbonate, and atomic oxygen at a mixed $\mathrm{Na}-\mathrm{Au}$ site (about $0.7 \mathrm{ML}$ ). While it could be appealing to associate the mixed $\mathrm{Na}-\mathrm{Au}$ sites with the bulk-terminated surface regions, XPD shows that oxygen disrupts the first few $\mathrm{NaAu}_{2}(111)$ layers. The other state is sodium oxide, associated with surface segregation of $\mathrm{Na}$. Formation of sodium oxide is strongly enhanced when adsorption occurs at $425 \mathrm{~K}$ because diffusion of sodium is facilitated. At higher temperature, loss of Na in XPS is due to desorption, and loss of oxygen is due to bulk dissolution. On surfaces that are initially Na-depleted, the oxide is suppressed preferentially and oxygen adsorption is suppressed overall. This is because depleted surfaces progressively revert to pure $\mathrm{Au}$, where oxygen is not stable. The reasons for good catalytic activity of powdered $\mathrm{NaAu}_{2}$ in $\mathrm{CO}$ oxidation may be more complex than envisioned initially.

Acknowledgements. This work was a collaboration between EMPA in Dübendorf, Switzerland, and Iowa State University in Ames, Iowa. Accordingly, this work was supported from two sources: the Swiss National Science Foundation (contract number (Contract 200021-129511), and the John D. Corbett Endowment of Iowa State University.

\section{References}

[1] M. Armbrüster, R. Schlögl, Y. Grin, Intermetallic compounds in heterogeneous catalysis-a quickly developing field, Sci. Technol. Adv. Mat., 15 (2014) 034803.

[2] A.P. Tsai, M. Yoshimura, Highly active quasicrystalline Al-Cu-Fe catalyst for steam reforming of methanol, Appl. Cat. A-Gen., 214 (2001) 237-241.

[3] K. Kovnir, M. Ambrüster, D. Teschner, T.V. Venkov, F.C. Jentoft, A. Knop-Gericke, Y.

Grin, R. Schlögl, A new approach to well-defined, stable and site-isolated catalysts, Sci.

Technol. Adv. Mat., 8 (2007) 420-427.

[4] M. Armbrüster, K. Kovnir, M. Friedrich, D. Teschner, G. Wowsnick, M. Hahne, P. Gille, L. Szentmiklosi, B. Feuerbacher, M. Heggen, F. Girgsdies, D. Rosenthal, R. Schlögl, Y. Grin, $\mathrm{Al}_{13} \mathrm{Fe}_{4}$ as a low-cost alternative for palladium in heterogeneous hydrogenation, Nat. Mater., 11 (2012) 690-693.

[5] A. Sanchez, S. Abbet, U. Heiz, W.-D. Schneider, H. Häkkinen, R.N. Barnett, U. Landman, When gold is not noble: Nanoscale gold catalysts, J. Phys. Chem. A, 103 (1999) 9573-9578. [6] A.S.K. Hashmi, G.J. Hutchings, Gold catalysis, Angew. Chem. Int. Edit., 45 (2006) 78967936.

[7] M. Haruta, M. Date, Advances in the catalysis of Au nanoparticles, Appl. Cat. A-Gen., 222 (2001) 427-437.

[8] B. Hvolbaek, T.V.W. Janssens, B.S. Clausen, H. Falsig, C.H. Christensen, J.K. Nørskov, Catalytic activity of Au nanoparticles, Nano Today, 2 (2007) 14-18.

[9] A. Wittstock, V. Zielasek, J. Biener, C.M. Friend, M. Baeumer, Nanoporous gold catalysts for selective gas-phase oxidative coupling of methanol at low temperature, Science, 327 (2010) 319-322. 
[10] L.-C. Wang, K.J. Stowers, B. Zugic, M.M. Biener, J. Biener, C.M. Friend, R.J. Madix, Methyl ester synthesis catalyzed by nanoporous gold: from $10^{-9}$ Torr to 1 atm, Catal. Sci. Technol., 5 (2015) 1299-1306.

[11] R. Meyer, C. Lemire, S.K. Shaikhutdinov, H. Freund, Surface chemistry of catalysis by gold, Gold Bull., 37 (2004) 72-124.

[12] C.X. Xiao, L.-L. Wang, R. Maligal-Ganesh, V. Smetana, H. Walen, P.A. Thiel, G.J. Miller, D.D. Johnson, W. Huang, Intermetallic $\mathrm{NaAu}_{2}$ as a heterogeneous catalyst for low-temperature CO oxidation, J. Am. Chem. Soc., 135 (2013) 9592-9595.

[13] M. Haruta, T. Kobayashi, H. Sano, N. Yamada, Novel gold catalysts for the oxidation of carbon monoxide at a temperature far below $0^{\circ} \mathrm{C}$, Chem. Lett., 4 (1987) 405-408.

[14] E.J. Kwolek, R. Widmer, O. Groening, O. Deniz, H. Walen, C.D. Yuen, W. Huang, D.L. Schlagel, M. Wallingford, P.A. Thiel, The (111) surface of $\mathrm{NaAu}_{2}$ : structure, composition, and stability, Inorg. Chem., 54 (2015) 1159-1164.

[15] K.C. Prince, G. Paolucci, A.M. Bradshaw, Oxygen-adsorption on silver (110) - dispersion, bonding and precursor state, Surf. Sci., 175 (1986) 101-122.

[16] K. Sakamoto, H.M. Zhang, R.I.G. Uhrberg, Adsorption and reaction processes of physisorbed molecular oxygen on Si(111)-(7x7), Phys. Rev. B, 72 (2005) 075346.

[17] K.W. Kolasinski, Surface Science: Foundations of Catalysis and Nanoscience, John Wiley \& Sons Ltd, Chichester, West Sussex, England, 2002.

[18] CasaXPS: Processing Software for XPS, AES, SIMS and More, in, 2009.

[19] A. Winkler, J.T. Yates Jr., Capillary array dosing and angular desorption distribution measurements: a general formalism, J. Vac. Sci. Technol. A, 6 (1988) 2929-2932.

[20] C.T. Campbell, S.M. Valone, Design considerations for simple gas dosers in surface science applications, J. Vac. Sci. Technol. A, 3 (1985) 408-411.

[21] J.H. Scofield, Hartree-Slater subshell photoionzation cross-sections at 1254 and 1487eV, J. Electron Spectrosc., 8 (1976) 129-137.

[22] S. Tanuma, C.J. Powell, D.R. Penn, Calculations of electron inelastic mean free paths. IX. Data for 41 elemental solids over the $50 \mathrm{eV}$ to $30 \mathrm{keV}$ range, Surf. Interface Anal., 43 (2011) 689-713.

[23] A. Jablonski, C.J. Powell, Information depth and the mean escape depth in Auger electron spectroscopy and X-ray photoelectron spectroscopy, J. Vac. Sci. Technol. A, 21 (2003) 274-283. [24] J.F. Moulder, W.F. Stickle, P.E. Sobol, K.D. Bomben, Handbook of X-ray Photoelectron Spectroscopy: a reference book of standard spectra for identification and interpretation of XPS data, Perkin-Elmer Corporation, Physical Electronics Division, Eden Prairie, Minnesota, 1992. [25] A. Barrie, F.J. Street, Auger and X-ray photoelectron spectroscopic study of sodium metal and sodium oxide, J. Electron Spectrosc., 7 (1975) 1-31.

[26] D.D. Wagman, W.H. Evans, V.B. Parker, R.H. Schumm, I. Halow, S.M. Bailey, K.L. Churney, R.L. Nuttall, The NBS tables of chemical and thermodynamic properties, J. Phys. Chem. Ref. Data, 11 (1982) Suppl. 2.

[27] R.J. Behm, C.R. Brundle, On the formation and bonding of a surface carbonate on Ni(100), Surf. Sci., 255 (1991) 327-343.

[28] A.V. Shchukarev, D.V. Korolkov, XPS study of group IA carbonates, Cent. Eur. J. Chem., 2 (2004) 347-362.

[29] K. Motzfeldt, The thermal decomposition of sodiumcarbontae by the effusion method, J. Phys. Chem., 59 (1955) 139-147. 
[30] J.J. Pireaux, M. Chtaib, J.P. Delrue, P.A. Thiry, M. Liehr, R. Caudano, Electron spectroscopic characterization of oxygen adsorption on gold surfaces: I. Substrate impurity effects on molecular oxygen adsorption in ultra high vacuum, Surf. Sci., 141 (1984) 211-220. [31] N.D.S. Canning, D. Outka, R.J. Madix, The adsorption of oxygen on gold, Surf. Sci., 141 (1984) 240-254.

[32] T. Visart de Bocarme, T.D. Chau, F. Tielens, J. Andres, P. Gaspard, R.L.C. Wang, H.J. Kreuzer, N. Kruse, Oxygen adsorption on gold nanofacets and model clusters, J. Chem. Phys., 125 (2006) 054703.

[33] S.A.C. Carabineiro, B.E. Nieuwenhuys, Adsorption of small molecules on gold single crystal surfaces, Gold Bull., 42 (2009) 288-301.

[34] H. Qiao, T. Nohira, Y. Ito, Electrochemical formation of $\mathrm{Au}_{2} \mathrm{Na}$ alloy and the characteristics of $\left(\mathrm{Au}_{2} \mathrm{Na}+\mathrm{Au}\right)$ reference electrode in a LiF-NaF-KF eutectic melt, Electrochim. Acta, 47 (2002) 4543-4549.

[35] B.K. Min, A.R. Alemozafar, M.M. Biener, J. Biener, C.M. Friend, Reaction of Au(111) with Sulfur and Oxygen: Scanning Tunneling Microscopic Study, Top. Catal., 36 (2005) 77-90. [36] J.A. Rodriguez, M. Pérez, T. Jirsak, J. Evans, J. Hrbek, L. González, Activation of Au nanoparticles on oxide surfaces: reaction of $\mathrm{SO}_{2}$ with $\mathrm{Au} / \mathrm{MgO}(100)$, Chem. Phys. Lett., 378 (2003) 526-532. 

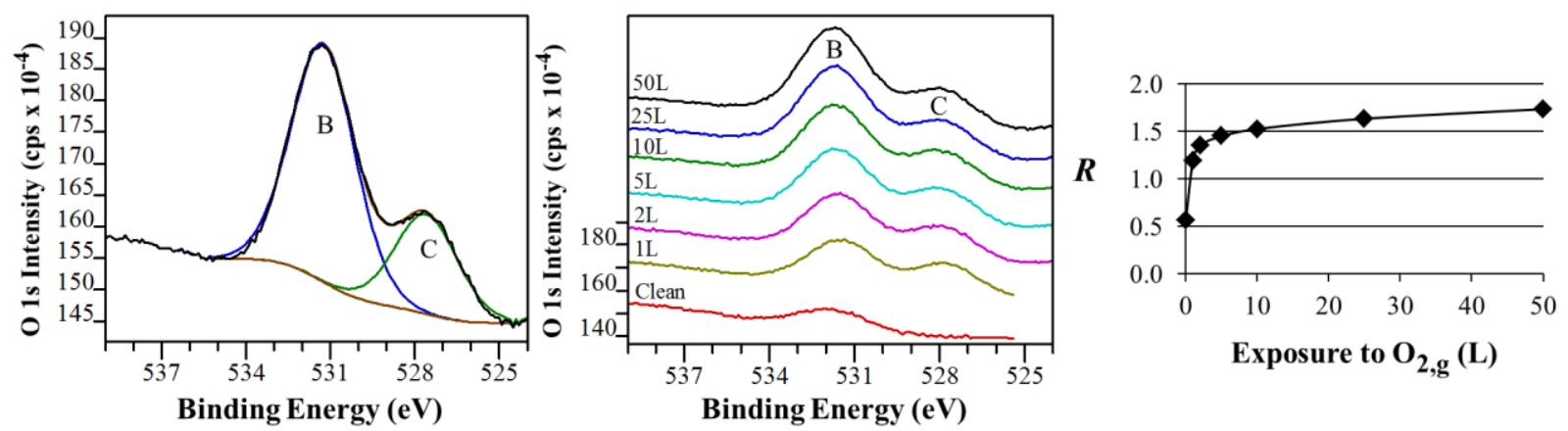